\title{
Winter saprolegniosis in channel catfish
}

\author{
J. E. Bly ${ }^{1}$, L. A. Lawson ${ }^{1}$, D. J. Dale ${ }^{1}$, A. J. Szalai ${ }^{1}$, R. M. Durborow ${ }^{2, *}$, L. W. Clem ${ }^{1}$ \\ ${ }^{2}$ Department of Microbiology, University of Mississippi Medical Center, Jackson, Mississippi 39216-4505, USA \\ ${ }^{2}$ Mississippi Cooperative Extension Service, Stoneville, Mississippi 38776, USA
}

\begin{abstract}
Pure cultures of fungus were isolated from commercially raised channel catfish Ictalurus punctatus exhibiting overt signs of a winter syndrome locally termed 'winter kill' The fungal isolates were identified as members of the genus Saprolegnia. Histopathological examination of fungal associated skin lesions from diseased fish exhibited a complete lack of bacteria or of leukocytic infiltration around the site(s) of hyphal penetration. In order to determine if the fungus was the origin of disease or an opportunistic secondary pathogen, controlled laboratory studies were conducted which conclusively proved that if channel catfish were immunosuppressed by a rapid decrease in environmental water temperature from 22 to $10^{\circ} \mathrm{C}$, the Saprolegnia sp. isolates rapidly infected catfish to cause $92 \%$ infection (skin lesions) and $67 \%$ mortality within $21 \mathrm{~d}$ post-challenge. Examination of laboratory-infected fish revealed fungal associated skin lesions with histopathology identical to that obtained from fish in the field, i.e. there was a complete lack of bacterial or leukocytic infiltration around the lesion site. These results strongly suggest that 'winter kill' syndrome in catfish is an immunodeficiency disease of fungal rather than bacterial etiology and is probably better termed 'winter saprolegniosis'
\end{abstract}

\section{INTRODUCTION}

Channel catfish Ictalurus punctatus cultured in earthen ponds in the southern U.S. frequently suffer from a syndrome locally termed 'winter kill', during the months from October to March. This sydrome can result in mass mortalities and major financial losses to the industry and is quite distinct from seasonal mortalities caused by ice cover-induced anoxia in the northern U.S., also termed 'winter kill'. Until this study, the southern 'winter kill' syndrome was ill-defined and the causative factors and etiology were unknown; the classical signs have been described as including fungal associated skin lesions, a 'dry', mucus-depleted skin, and sunken eyes (Durborow \& Crosby 1988). A clue to understanding this disease resulted from the observations of farmers that the appearance of 'winter kill' followed the passage of a severe cold weather front, wherein pond water temperatures changed rapidly (i.e. decreased as much as 5 to $9^{\circ} \mathrm{C}$ in $12 \mathrm{~h}$ ) and remained low $\left(6\right.$ to $12^{\circ} \mathrm{C}$ ) for 1 to $4 \mathrm{wk}$. Since previous laboratory experiments had indicated that such abrupt decreases in tank water temperature (i.e. from 22 to $12^{\circ} \mathrm{C}$ over

- Present address: Aquaculture Research Center, Kentucky State University, Frankfort, Kentucky 40601, USA
24 h) clearly rendered catfish immunocompromised until their leukocytes underwent homeoviscous (thermal) adaptation (Hazel 1984) to the new low temperature (Bly \& Clem 1991a, b), it appeared that temperature might be a key factor in this syndrome. It was therefore postulated that 'winter kill' of catfish in the southern US was a low temperature-mediated immunodeficiency disease with mortalities resulting from invasion by one or more opportunistic microorganisms.

To test this hypothesis, channel catfish were sampled from commercial ponds during winter 1990 to isolate microorganisms associated with the disease and determine if these were primary or secondary invaders. Koch's postulates (Koch 1884, Joklik et al. 1988) were followed to identify the potential causative agent(s) of the syndrome. Minimal requirements to reproducibly induce signs of 'winter kill' in catfish were established using controlled laboratory conditions simulating those observed in commercial ponds.

\section{MATERIALS AND METHODS}

Ponds, fish, and water quality. Fish were collected from 4 commercial production ponds at Dyche Plantation catfish farm, Mississippi, USA (designated 6B, 8B, 
13A, and 16A) during January and March 1990 after the owners reported increasing fish mortalities. Twelve live fish were caught by snagging, dip net or seine at each sampling time and 4 fish submitted for routine diagnostic examination (Amos 1985) at the Mississippi Cooperative Extension Service Fish Disease Diagnostic Laboratory. Water quality parameters, temperature, $\mathrm{pH}$, total ammonia nitrogen (TAN), and oxygen were assayed in the field with commercially available kits (Hach Company, Loveland, CO, USA). Toxic (unionized) ammonia levels were calculated in the laboratory from temperature, $\mathrm{pH}$, and TAN values according to Emerson et al. (1975). Pond water collected in $500 \mathrm{ml}$ sterile bottles was transported to the laboratory at ambient temperature for subsequent culture of microorganisms (see below).

Mycology. Skin sections (ca $10 \times 15 \mathrm{~mm}$ ) were taken from healthy fish, and from areas that appeared infection-free and the periphery of well-defined lesions on diseased fish. One half of each section was fixed in formalin for histopathological examination and the other half cultured for isolation of micro-organisms. Histological sections were prepared using standard procedures and stained with hematoxylin and eosin (HE), periodic acid-Schiff (PAS), Giemsa (G), and the Grocott modification of Gomori methenamine silver stain (GMS). Tissues for culture were washed in 2 changes of sterile water, cut in half, and placed skin side down on separate plates containing $20 \mathrm{ml}$ of Corn Meal Agar (CMA, Difco, 1386) with $150 \mathrm{mg} \mathrm{l}^{-1}$ penicillin (P) and $250 \mathrm{mg} \mathrm{l}^{-1}$ streptomycin (S) added to slow growth of bacteria and permit the isolation of fungi (Willoughby \& Pickering 1977). One plate was incubated at $23^{\circ} \mathrm{C}$ and the other at $11^{\circ} \mathrm{C}$ with daily inspection and microphotography of fungal growth. Small (ca $5 \times 5 \mathrm{~mm}$ ) blocks of agar were cut from the periphery of any fungal growth that occurred and placed, hyphae down, on a new CMA plate to subculture and isolate the fungus. The hemp seed (Cannabis sativa L.) culture method (Seymour 1970) was used to transfer fungal isolates to petri dishes of autoclaved pond water. Fungal isolates (designated CF1 to CF8) were identified morphologically according to Coker (1923) and Seymour (1970) using Saprolegnia parasitica (ATCC 22284) and Saprolegnia diclina (ATCC 42062; Roberts 1989) for comparative purposes. One fungal isolate (CF1) and the ATCC isolates were sent to Dr Roland Seymour (Dept. Plant Biology, Ohio State Univ, USA) and independently identified.

Fungi from pond water were also routinely grown on CMA containing an intermediate dose of antibiotics (36 $\mathrm{mg} \mathrm{l}^{-1} \mathrm{P}$ and $60 \mathrm{mg} \mathrm{l}^{-1} \mathrm{~S}$ ) because fungal zoospore encystment and hyphal development is inhibited by the higher antibiotic doses used in skin fungal cultures (L. G. Willoughby pers. comm.). Aliquots $(0.5 \mathrm{ml})$ of sampled pond water were inoculated onto 20 plates spread, and 10 plates each incubated at $23^{\circ} \mathrm{C}$ and $11^{\circ} \mathrm{C}$. Fungal and bacterial colonies were counted daily and expressed as mean number of colonies formed per $\mathrm{ml}$ of pond water. No attempts were made to identify the fungi from pond water that were morphologically dissimilar to fungus from diseased channel catfish or the numerous bacteria present.

Challenge experiments. Juvenile channel catfish (50 to $150 \mathrm{~g}$ ) were transported from a local hatchery, acclimated to laboratory conditions (recirculating $250 \mathrm{l}$ nalgene tanks, 30 fish per tank, $22^{\circ} \mathrm{C}$ ) for at least $4 \mathrm{wk}$, and fed to satiation every other day with floating catfish chow (Ralston Purina). Various challenge protocols were conducted comprising 12 individual experiments. In each challenge experiment, groups of 6 to 15 fish (depending on size) were moved to previously disinfected $30 \mathrm{l}$ nalgene tanks with biological filters and air supplies secured to the center of the tank. The tanks were inserted into $100 \mathrm{l}$ tanks which acted as water jackets, and water was circulated through a sump containing refrigeration units (Frigid Units Inc, Toledo, $\mathrm{OH}, \mathrm{USA}$ ). Catfish were quickly moved from holding to challenge tanks and left for $24 \mathrm{~h}$ to acclimate to their new surroundings. Moved fish were immunologically normal $24 \mathrm{~h}$ post-transport as determined by leukocyte proliferation in mitogen assays, 2-way mixed lymphocyte reactions and peripheral blood neutrophil counts (data not shown; Faulmann et al. 1983, Ellsaesser \& Clem 1986, Miller et al. 1986, Bly et al. 1990).

Tank water temperature, $\mathrm{pH}, \mathrm{TAN}$, and dissolved oxygen levels were measured with commercial kits (CHEMetrics, Inc, Calverton, VA, USA) and un-ionized ammonia levels calculated as described previously. Water fungal and bacterial colony counts were also taken (see above). Hemp seeds infested with a fungal isolate were cut from CMA plates and added to a floating net secured in the center of the tank. Another seed was cultured in a dish of sterile pond water at the challenge temperature to verify zoospore production. Initially 15 hemp seeds were added to each challenge tank to obtain high zoospore levels (50 to $100 \mathrm{ml}^{-1}$ ) as used in experiments by others where brown trout were challenged with zoospores of the Saprolegnia diclinaS. parasitica complex (Wood et al. 1988). Subsequently, 5 hemp seeds were used per tank to duplicate zoospore counts observed in 'winter kill' affected commercial ponds (5 to $10 \mathrm{ml}^{-1}$ ). After the hemp seeds were added, the water jacket was chilled from ambient $\left(22^{\circ} \mathrm{C}\right)$ to $10 \pm 1^{\circ} \mathrm{C}$ during a $24 \mathrm{~h}$ period in order to immunosuppress the fish (Bly \& Clem 1991a). Tanks were subsequently maintained at either $10^{\circ} \mathrm{C}$ or at ambient temperature (control) for 3 wk before the experiment was terminated. The $3 \mathrm{wk}$ period was chosen because in commercial ponds water temperatures rarely stay 
$\leq 10^{\circ} \mathrm{C}$ for longer than $3 \mathrm{wk}$ (Bly unpubl.). Additional control experiments included (a) fish chilled as above but not challenged and (b) fish acclimated at $10^{\circ} \mathrm{C}$ for 8 wk (Bly et al. 1991 b) before challenge. Ten replicate water sample plates were prepared and incubated at $11^{\circ} \mathrm{C}$ or at tank temperature to count colony forming fungal zoospores and/or bacteria. Skin sections from diseased fish were cultured and processed for histopathological examination as already described. In order to minimize amplification of zoopore numbers by fungal reproduction on dead fish, the latter were removed from challenge tanks immediately after death. This ensured that zoospore numbers did not increase over Day 8 post-challenge values when assayed later on Days 14 or 21.

Statistical analyses were conducted using paired, 2tailed Student's $t$-test methods, wherein a probability of 0.05 or less was considered significant.

\section{RESULTS}

\section{Field observations}

In January 1990 each of 12 catfish randomly collected from Pond 16A were healthy, whereas each of 12 catfish collected from Pond $6 \mathrm{~B}$ were diagnosed as exhibiting signs of 'winter kill', i.e. they exhibited moderate to light external fungal infections associated with multiple dorsal, ventral and lateral skin lesions characteristic of the 'winter kill' syndrome. Lesions ranged in size from $0.5 \mathrm{~cm}$ in diameter to affecting one-third of the fish's torso. Smaller lesions were typically covered in yellow-brown, cotton-like fungal hyphae which could be pulled away to reveal a depressed hemorrhagic lesion. Larger lesions were surrounded by yellow-brown fungus; their centers were pitted and hemorrhagic and extended through the epidermis and dermis into the muscle. Similarly, fish sampled in March from Ponds 6B, 16A, 8B, and $13 \mathrm{~A}$ had visible external fungal growth associated with skin lesions. All affected fish exhibited endophthalmia and gill epithelial tissue was grossly hyperplastic. Water quality was assessed in Ponds 6B and 16A: in January the temperature was $10^{\circ} \mathrm{C}$ in both ponds, TAN levels were 10 and $8 \mathrm{mg} \mathrm{l}^{-1}$, and un-ionized ammonia values were 0.182 and $0.145 \mathrm{mg} \mathrm{l}^{-1}$, respectively. In March the pond water temperatures were 20 and $21^{\circ} \mathrm{C}$, TAN levels

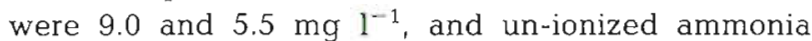
values were 0.035 and $0.023 \mathrm{mg} \mathrm{l}^{-1}$ for Ponds $6 \mathrm{~B}$ and $16 \mathrm{~A}$, respectively.

\section{Mycology}

Skin lesions from 22 fish with 'winter kill' collected in January and March and skin samples from 4 healthy fish were cultured on CMA plates at 23 and $11^{\circ} \mathrm{C}$. No fungi grew from healthy fish skin while all lesion samples provided homogeneous and rapid fungal growth at both temperatures, i.e. hyphae were fine, white, and non-aerial and grew ca $0.5 \mathrm{~cm}$ in length $\mathrm{d}^{-1}$ at $11^{\circ} \mathrm{C}$ and $\mathrm{ca} 1 \mathrm{~cm} \mathrm{~d} \mathrm{~d}^{-1}$ at $23^{\circ} \mathrm{C}$. Other morphologically different fungi, bacteria and/or protozoan parasites did not appear to be present in these skin lesions. Fungal subcultures transferred to pond water formed secondary sporangia arising from the basal septum of empty primary sporangia (Fig. 1), and zoospores demonstrated diplanetism with rapidly swimming primary and slightly larger slower secondary forms. These morphological features are characteristic of the genus Saprolegnia (Seymour 1970, Alexopoulos 1979). Empty asexual sporangia, a possible gemma, a typical zoospore and an encysted zoospore of one of the catfish isolates (CF1) are illustrated in Fig. 1. Based on these characteristics the organism was tentatively identified as a member of the genus Saprolegnia, an identification confirmed by Dr Seymour.

Analyses of 8 fungal isolates obtained from 'winter kill' skin lesion cultures indicated surprising morphological homogeneity suggesting that the same member of the genus Saprolegnia is associated with 'winter kill' All 8 catfish isolates were morphologically distinct from the ATCC isolates, e.g. S. diclina formed antheridia and oogonia in pond water cultures while $S$. parasitica and the catfish isolates did not. Furthermore when grown in Leibovitz's L-15 medium (GIBCO Laboratories, Grand Island, New York, USA) S. parasitica and $S$. diclina produced only hyphae while all catfish isolates produce hyphae and spherical, gemmalike, structures. Consequently our 8 fungal isolates were termed Saprolegnia sp. and designated CF1 through CF8.

Histopathological examination of skin sections stained with GMS from moribund fish exhibiting 'winter kill' revealed mats of fungal hyphae (identified as Saprolegnia sp. from simultaneous cultures) over the surface of the fish (Fig. 2b) with hyphae apparent both deep in and at the surface of the degenerated dermis (Fig. 2c). Numerous sections stained with $\mathrm{G}, \mathrm{HE}$ or PAS indicated that within the living tissue there was a complete lack of bacteria or infiltrating catfish leukocytes (the latter are ca 4 to $10 \mu \mathrm{m}$ in diameter, similar to the diameter of the fungal hyphae; Fig. 2c). A histological section from the skin of a healthy fish stained with GMS is shown for comparative purposes; the intact epidermis containing mucus secreting cells (staining black) is seen above the dermis (Fig. 2a).

Pond water cultures contained numerous fungi and bacteria, although when cultured at $11^{\circ} \mathrm{C}$ Saprolegnia sp. colonies similar to those observed from infected catfish skin samples were seen, i.e. hyphae grew at a 

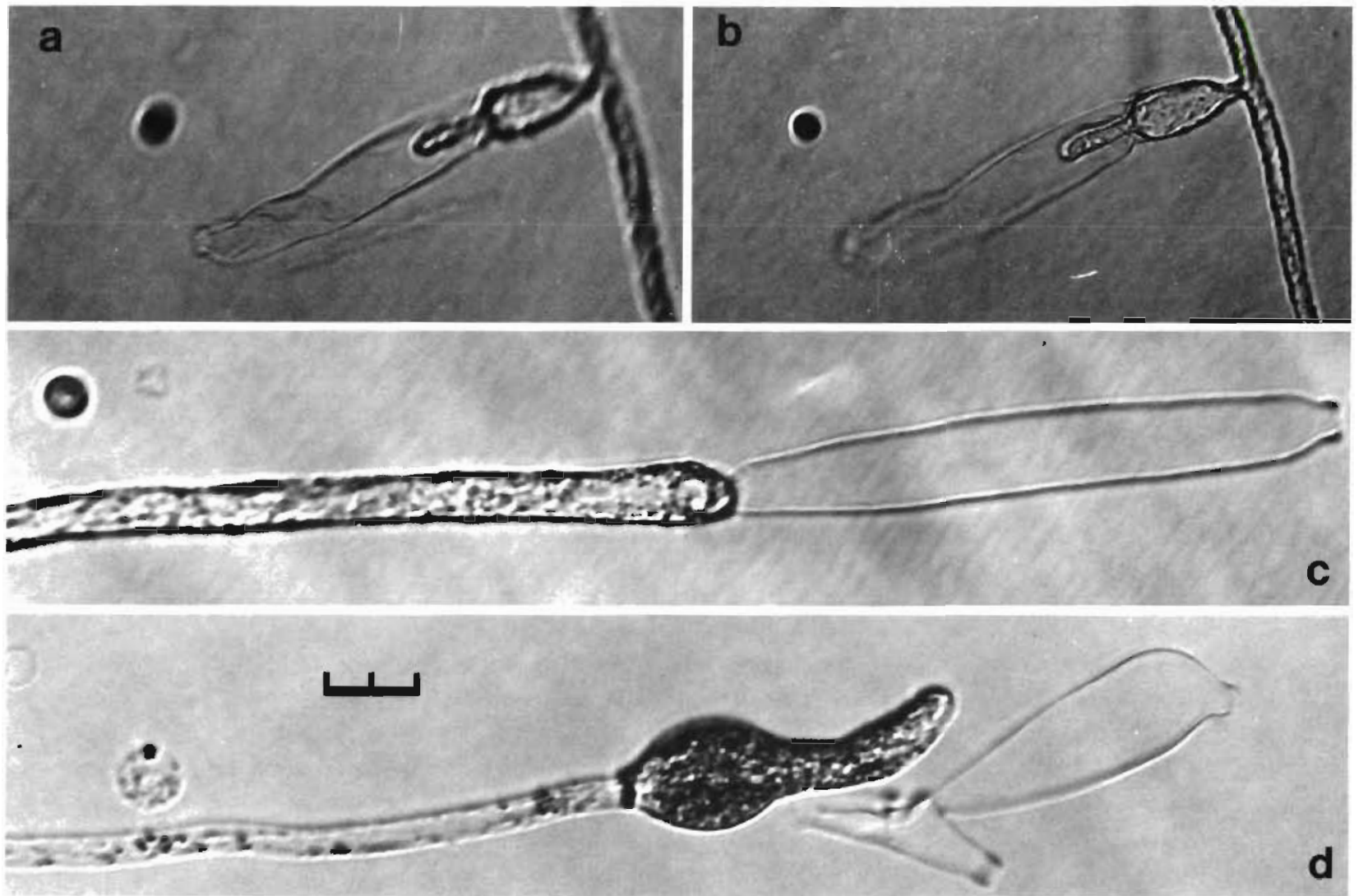

Fig. 1. Saprolegnia sp. Morphology of 'winter kill' fungus cultured in sterile, autoclaved pond water. The morphology characteristic of the genus can be seen in 2 focal planes in (a) and (b), i.e. a secondary sporangium arising from the basal septum of an empty primary sporangium. (c) and (d): Typical empty sporangia formed at the tips of hyphae; (d): a possible gemma. In (c) a small (ca $10 \mu \mathrm{m}$ ) primary zoospore is present while in (d) a larger (ca $12 \mu \mathrm{m}$ ) encysted zoospore can be seen. Scale bar $=20 \mu \mathrm{m}$

rate of ca $0.5 \mathrm{~cm} \mathrm{~d}^{-1}$ and rapidly outgrew bacterial and other fungal colonies. When cultured at $23^{\circ} \mathrm{C}$ Saprolegnia sp. did not dominate and was rapidly overgrown by other organisms unless present at $\geq 4$ colonies $\mathrm{ml}^{-1}$ water when it again dominated the cultures (data not shown). For this reason $11^{\circ} \mathrm{C}$ cultures were routinely used to estimate Saprolegnia sp. colony numbers.

Saprolegnia sp. colony forming zoospores were most numerous in pond water in January when water temperatures were coldest $\left(10^{\circ} \mathrm{C}\right)$, ranging from 5 to 10 zoospores $\mathrm{ml}^{-1}$. In March when the water temperatures were higher $\left(20^{\circ} \mathrm{C}\right)$, Saprolegnia sp. zoospore levels were lower, ranging from 2 to $6 \mathrm{ml}^{-1}$.

\section{Challenge experiments}

Field observations indicated a possible correlation between low water temperatures (ca $10^{\circ} \mathrm{C}$ ), Saprolegnia sp. zoospore levels ( 5 to $10 \mathrm{ml}^{-1}$ ), and outbreaks of 'winter kill' In order to determine the interrelationships of such observations, laboratory challenge exper- iments were conducted; the results are given in Table 1 and several observations warrant comment. Day 0 fungal colony counts indicated that laboratory tank water contained low levels of viable Saprolegnia sp. colony forming zoospores $\left(\leq 1 \mathrm{ml}^{-1}\right)$. When challenges with 15 Saprolegnia sp. infested hemp seeds were conducted at ambient temperature $\left(22^{\circ} \mathrm{C}\right.$ ) (Table 1, Protocol no, 1), zoospore counts remained at baseline levels over a 3 wk period and fish did not become infected. Furthermore, when fish were subjected to an abrupt decrease in water temperature but not challenged (Table 1 . Protocol 2), Saprolegnia sp. zoospore numbers remained at baseline levels and the fish remained healthy. When fish were acclimated to $10^{\circ} \mathrm{C}$ for 8 wk and then challenged with CF1, no mortalities were observed although zoospore levels were high, 8 to 12 $\mathrm{ml}^{-1}$ (Table 1, Protocol 3). Furthermore, when fish were immunosuppressed by the temperature decrease and challenged with $S$, parasitica or $S$. diclina (Table 1, Protocols 4 \& 5, respectively) no mortalities were recorded. In fact in Protocols 3 to 5 the few infected fish seen after $3 \mathrm{wk}$ only exhibited fungus around the 


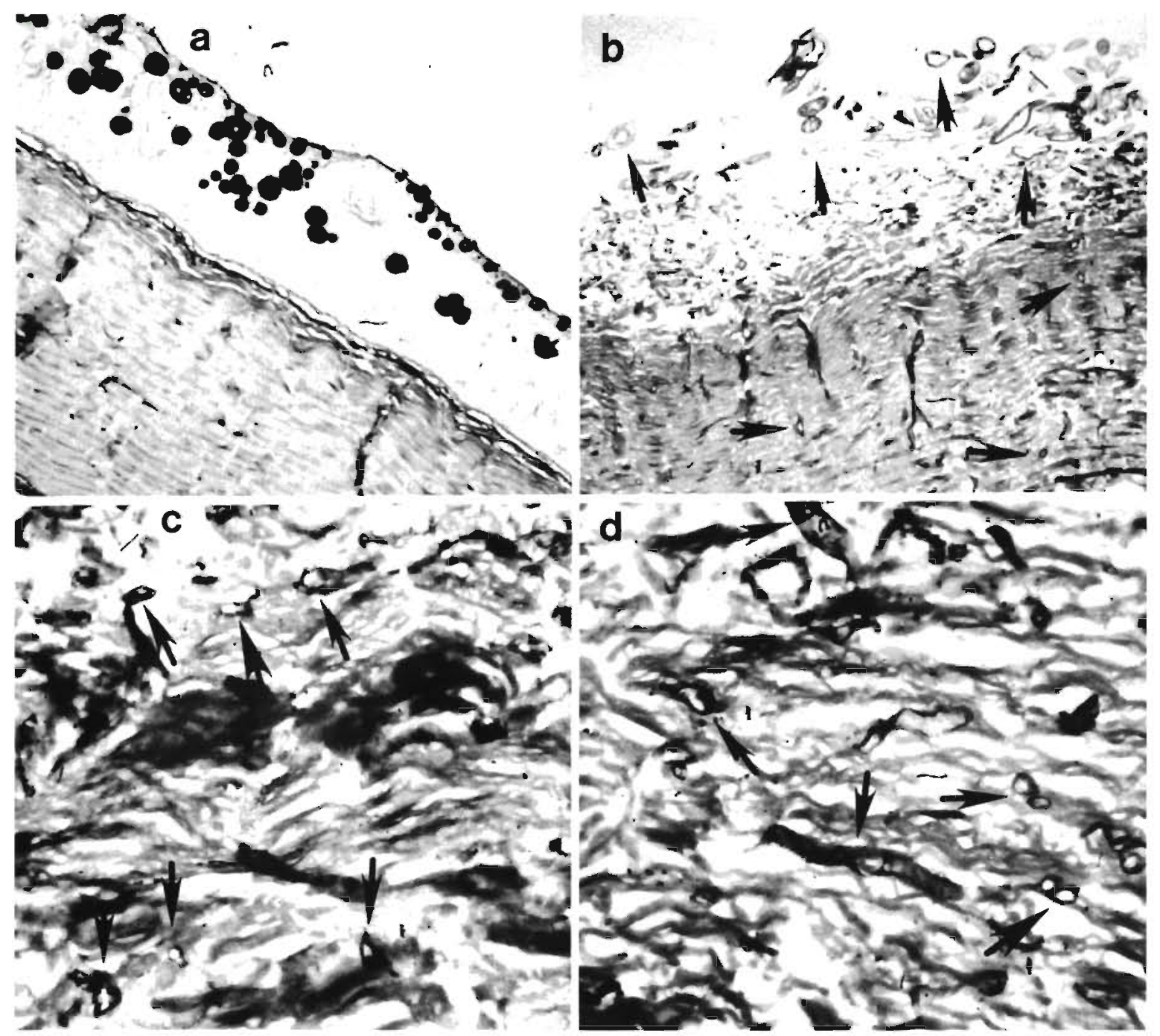

Fig. 2. Ictalurus punctatus. Histological examination of skin sections stained with GMS, taken from a healthy pond catfish (a, $200 \times$ ) and a lesion taken from a pond catfish exhibiting 'winter kill' (b, 200x). Fungal hyphae present at the degenerated dermal surface of the lesion and deep in the dermis are indicated by arrows (b). The epidermis containing mucus secreting cells (staining black in a) has been totally destroyed. (c) and (d): Lesions from pond infected and laboratory infected fish, respectively (800x). At this magnification fungal hyphae are easily seen in the dermis (arrows) while the lack of leukocytes around the invading hyphae is also apparent

margins of the ventral fins; there were no visible skin lesions, or lateral line or dorsal fin involvement. In Protocols 6 to 10 (Table 1 ), a combination of a rapid decrease in water temperature and elevated fungal zoospore levels averaging 12 to $20 \mathrm{ml}^{-1}$ resulted in the average of $25 \%$ of the fish challenged exhibiting 'winter kill' associated fungal skin lesions and $16 \%$ mortality at $8 \mathrm{~d}$ post-challenge, $85 \%$ infection and $45 \%$ mortality at 2 wk post-challenge and $92 \%$ infection and $67 \%$ mortality at 3 wk post-challenge. Although isolates CF1, CF3, CF4 and CF5 appeared to differ in virulence, they each infected and killed significant numbers of catfish within 1 to $2 \mathrm{wk}$. Statistical analyses, comparing experiments within Protocol 1 with those in
Protocols 2 to 5 , indicated no significant differences. Comparing Protocol no. 1 with Protocols 6 to 10 indicated that the numbers of infected fish on Days 8,14 and 21 were all significantly different compared with the control experiments except for Protocol 6, Day 8 where $p=0.22$. The latter result may indicate decreased virulence with increased fungal population size. Experimentally infected fish are depicted in Fig. 3. Gross pathology included masses of fungal hyphae on all or some of the fins, particularly the dorsal fin and tail, and small fungal colonies forming along the length of the lateral line, gills, nares, and anus. If the masses of hyphae were gently pulled away from the skin, hemorrhagic depressions were evident. Raised 'lumps of 
Table 1 Laboratory challenge experiments. Channel catfish Ictaurus punctatus were challenged with Saprolegnia sp. isolates obtained from 'winter kill infected fish designated CF1, CF3, CF4, or CF5, or with ATCC isolates Saprolegnia parasitica (SP) or $S$. diclina (SD), and mean number of zoospores $\mathrm{ml}^{-1}$ tank water and cumulative numbers of fish infected and dead were determined after the specified number of days

\begin{tabular}{|c|c|c|c|c|c|c|c|c|c|}
\hline \multirow[t]{2}{*}{ Protocol } & \multirow[t]{2}{*}{ Isolate } & \multirow{2}{*}{$\begin{array}{l}\text { Temp. } \\
\left({ }^{\circ} \mathrm{C}\right)\end{array}$} & \multirow{2}{*}{$\begin{array}{l}\text { No. } \\
\text { fish }\end{array}$} & \multicolumn{3}{|c|}{ Zoospores $\mathrm{ml}^{-1}$} & \multicolumn{3}{|c|}{ No infected (no. dead) } \\
\hline & & & & Day 0 & Day 4 & Day 8 & Day 8 & Day 14 & Day 21 \\
\hline $1^{a}$ & $\mathrm{CF} 1^{\circ}$ & $22 \rightarrow 22$ & 20 & 0 & 0 & 0 & $0(0)$ & $0(0)$ & $0(0)$ \\
\hline $2^{a}$ & None & $22 \rightarrow 10$ & 28 & 0 & 1 & 1 & $0(0)$ & $0(0)$ & $0(0)$ \\
\hline $3^{a}$ & CF1 & $10 \rightarrow 10$ & 17 & 0 & 8 & 12 & $0(0)$ & $0(0)$ & $4(0)$ \\
\hline 4 & SP & $22 \rightarrow 10$ & 6 & 0 & 5 & 6 & $0(0)$ & $0(0)$ & $2(0)$ \\
\hline 5 & $\mathrm{SD}$ & $22 \rightarrow 10$ & 7 & 0 & 6 & 6 & $0(0)$ & $0(0)$ & $2(0)$ \\
\hline $6^{\mathrm{a}}$ & $C F 1^{b}$ & $22 \rightarrow 10$ & 12 & 1 & 108 & 120 & $1(0)$ & $10(2)$ & $12(7)$ \\
\hline $7^{a}$ & CF1 & $22 \rightarrow 10$ & 86 & 1 & 17 & 18 & $14(8)$ & $49(33)$ & $75(55)$ \\
\hline $8^{\mathrm{a}}$ & CF3 & $22 \rightarrow 10$ & 12 & 1 & 24 & 18 & $9(6)$ & $10(7)$ & $12(8)$ \\
\hline 9 & CF4 & $22 \rightarrow 10$ & 6 & 0 & 46 & - & $2\{1\}$ & $6(6)$ & - \\
\hline $10^{\mathrm{a}}$ & CF5 & $22 \rightarrow 10$ & 12 & 1 & 22 & 12 & $8(5)$ & $10(10)$ & $12(10)$ \\
\hline
\end{tabular}

mucus' were also apparent over the otherwise 'dry' skin around the head and/or associated with the lateral line. These 'lumps of mucus' were shown by direct microscopic examination to contain hyphae and were determined (by skin culture techniques, see 'Materials and methods') to be emerging fungal colonies. Some fish also appeared to be lethargic or disorientated (i.e. they swam at the water surface) and many had discolored skin and endopthalmia. In all cases, skin cultures prepared from laboratory-infected fish yielded fungal growth indistinguishable from the isolate used in the challenge; these new isolates were designated CF1', CF3', CF4', and CF5'. Furthermore, although the infection was invasive and histopathology indicated hyphal penetration deep into the dermis and muscle of live tissue, systemic infections were not observed when organs from moribund fish were cultured using the skin culture technique (see 'Materials and methods'). Histopathology also indicated a complete lack of bacterial infection around the penetrating fungal hyphae and no sign of any leukocytic infiltration (Fig. 2D).

\section{DISCUSSION}

Channel catfish ponds were sampled during the winter of 1990 to identify environmental parameters and the causative microbial agent(s) which may influence outbreaks of the winter syndrome locally termed 'winter kill' in channel catfish. Results indicated that occurrences of 'winter kill' in channel catfish ponds may be correlated with rapid decreases in water temperatures (to $\mathrm{ca} 10^{\circ} \mathrm{C}$ ) known to induce in vivo immunosuppression in channel catfish held in the laboratory (Bly \& Clem 1991a) and with the presence of a ubiquitous fungus identified as a member of the genus Saprolegnia. Koch's postulates were followed and fullfilled in laboratory studies conducted to test the relationships between temperature and the pathogenicity of isolated Saprolegnia sp. Specifically. Saprolegnia sp. was isolated from moribund, but not healthy, pond catfish and grown in pure culture in the laboratory. These isolates were then used in controlled laboratory challenge experiments and found to infect and kill susceptible channel catfish. Saprolegnia sp. was subsequently isolated from experimentally infected fish. As such it appears that Saprolegnia sp. is an infectious pathogen for catfish and may be the causative agent in 'winter kill'. Furthermore, the pathogenicity of Saprolegnia sp. was dependent on the susceptibility of the catfish, i.e. the catfish first had to be immunocompromised by a rapid decrease in environmental temperature (Bly \& Clem 1991a). These results corroborate observations made by catfish farmers who frequently note occurrences of 'winter kill' after passage of severe cold weather fronts. Further evidence to support this notion is derived from the use of immunocompetent channel catfish, i.e. those fish held at $22^{\circ} \mathrm{C}$ or acclimated to $10^{\circ} \mathrm{C}$ (Bly \& Clem 1991b) which remained healthy post-challenge. The inability of ATCC isolates S. parasitica or $S$. diclina to infect immunocompromised channel catfish was surprising considering that at comparable zoospore levels CF1 infects and kills catfish within 1 wk post-challenge (see below). These isolates may have lost thejr virulence and/or may simply not be pathogenic for channel catfish, points to be pursued in future experiments. Obviously these isolates differ in virulence when compared 


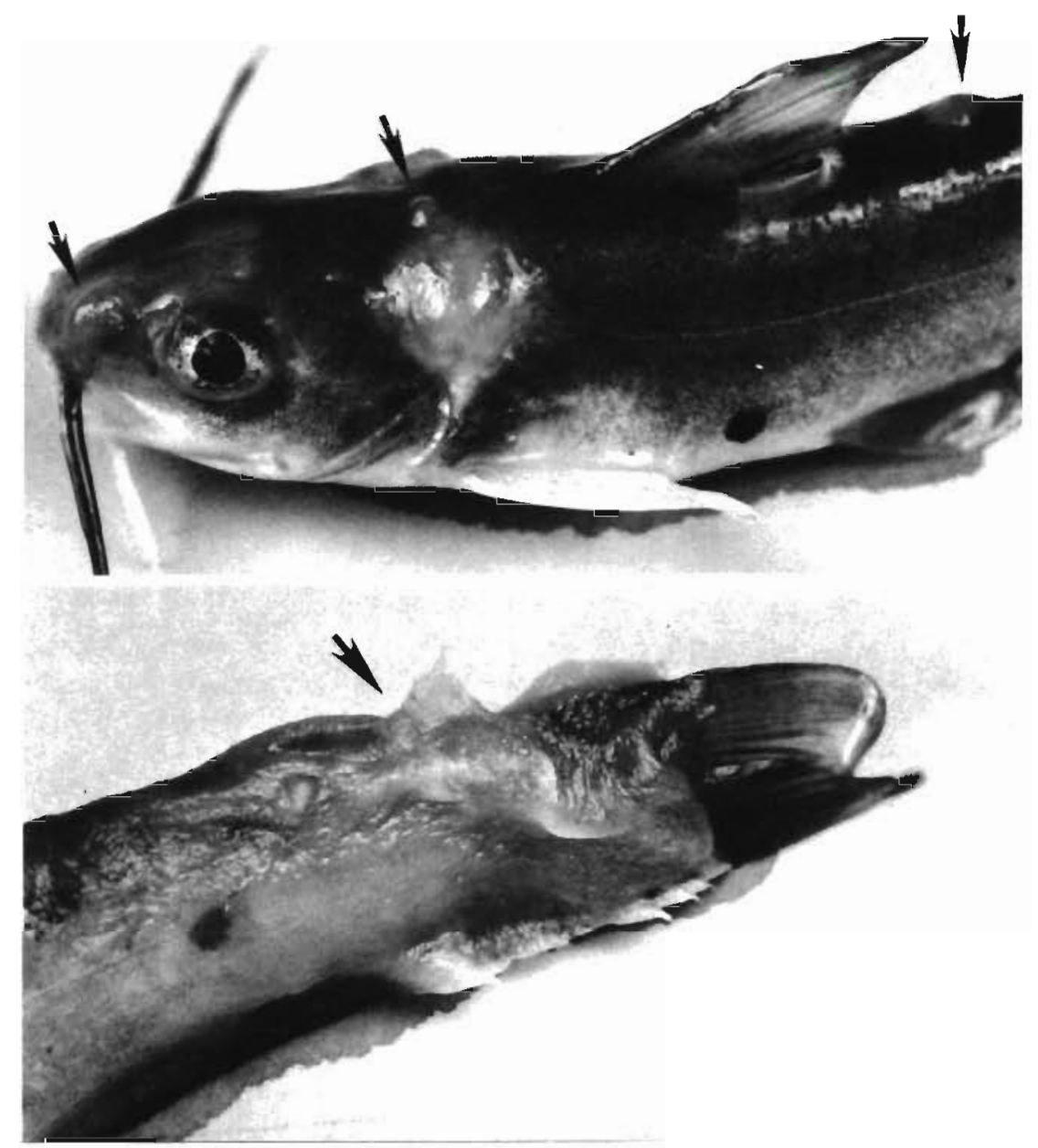

Fig. 3. Ictalurus punctatus. Experimentally infected fish exhibiting signs of 'winter kill' 2 wk post-challenge. The masses of fungal hyphae are evident around the nares and gills (top), tail (middle) and lateral line (bottom) and are marked by

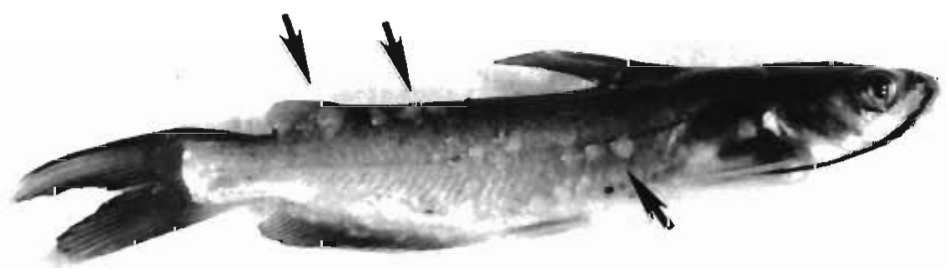
arrows

with CF1, CF3, CF4 and CF5 and this observation should facilitate identification of the virulence factor(s) responsible for the pathogenicity of our isolates.

Attempts to identify the Saprolegnia sp. isolates continue, both in our laboratory and that of Dr. Seymour. Classically, identification to the species level in this genus is based on the morphology of the oogonia and antheridia produced during the sexual phase of the fungal life cycle. However, to date, over 1 yr since we obtained our catfish isolates, the fungi have failed to produce oogonia and antheridia, although gemmae have been seen frequently. According to Coker (1923), if an isolated member of the genus Saprolegnia will not produce male and female reproductive structures, it is termed Saprolegnia sp. It would appear that other methodologies may be necessary to classify fungal isolates which belong to the genus Saprolegnia but fail to undergo asexual reproduction. In this regard, the recent use of polyclonal antibodies raised against a crude fungal homogenate of Saprolegnia parasitica was unsuccessful in exclusively recognizing this species of the genus Saprolegnia (Bullis et al. 1990). Consequently, we are now employing a combination of techniques used to differentiate closely related species of medical importance, e.g. cytofluorographic analyses (Taguchi et al. 1988), immunoassays employing anti- 
bodies directed against species-specific antigens (Schnur et al. 1990), and ribotyping (Thomson-Carter et al. 1989). The initial results indicate that our 8 catfish isolates studied are identical to one another, but differ from Saprolegnia diclina (ATCC 42062) and Saprolegnia parasitica (ATCC 22284) in temperature sensitivity, zoospore production, cytofluorographic analyses of zoospore autofluorescence, and protein composition (Bly unpubl.).

It seems clear from these studies that 'winter kill' is likely an environmental and man-made problem. In the southern U.S. during winter, air temperatures fluctuate rapidly over a wide range. Due to the design of commercial catfish ponds which have a Iarge surface area (ca 7 ha) coupled with shallow depth $(1.2$ to $1.8 \mathrm{~m}$ ), pond water temperatures change dramatically. Consequently, when water temperatures suddenly decrease, pond-raised catfish, unlike feral fish, cannot thermoregulate by moving towards a temperature of choice. Laboratory studies have shown that rapid decreases in tank water temperature designed to mimic those seen in commercial ponds during the winter months leave the fish immunosuppressed for a minimum of 3 to $5 \mathrm{wk}$ until the leukocytes undergo homeoviscous adaptation to the new low temperature (Bly \& Clem 1991a, b). All ectotherms undergo homeoviscous adaptation: after a change in environmental temperature the animal adapts by changing cellular plasma membrane composition to allow cells to function at the new temperature (Sinensky 1974, Hazel 1984, Cossins \& Bowler 1987). However, only recently has the effect of temperature on immune cell functions been examined, and studies in our laboratory have resulted in a basic understanding of the mechanisms involved in homeoviscous adaptation of channel catfish $\mathrm{T}$ and $\mathrm{B}$ lymphocytes (Bly et al. 1986, 1987, 1988, Bly \& Clem 1988). Briefly, homeoviscous adaptation takes time, ca 3 wk for in vivo acclimation from 22 to $17^{\circ} \mathrm{C}$ and ca $5 \mathrm{wk}$ for complete in vivo acclimation from 22 to $12^{\circ} \mathrm{C}$. Hypothetically, since channel catfish pond water temperatures are highly variable, it is likely that fish in commercial ponds spend the winter trying to 'catch up' with the rapidly changing temperatures, leaving the fish in an almost continual state of immunosuppression over the winter period. While results from both field and laboratory skin lesion histopathogy revealed a lack of leukocytic infiltration at the sites of hyphal penetration, supporting the notion of in vivo immunosuppression, additional studies are required to test this hypothesis.

It was surprising that only one type of fungus, rather than many fungi and bacteria, was associated with the 'winter kill' syndrome. A clue to understanding this situation comes from a recent report by MacMillan \& Santucci (1990) who studied the seasonal variability of intestinal bacterial flora in pond-raised channel catfish.
They noted that samples obtained in January were different from samples taken during other months. In fact, $61 \%$ of the fish sampled in January appeared to have sterile intestines. Furthermore, Aeromonas sp. and Escherichia coli were the only bacteria found year round. Their data, generated in 1983, indicated that January was the coldest month sampled, with water temperatures ranging from 5.5 to $8.5^{\circ} \mathrm{C}$. These data suggest that the bacterial species usually associated with water sources in the southern U.S. are primarily warm water species that, like catfish, also require time to acclimate to the periodic cold temperatures often associated with southern winters. In this regard it was interesting in the present study that internal examination conducted on the fish exhibiting 'winter kill' from Pond $6 \mathrm{~B}$ in January (temperature $=10^{\circ} \mathrm{C}$ ) were unremarkable with no bacterial growth observed in culture. However, in March, after water temperatures had increased to $20^{\circ} \mathrm{C}$, fish exhibiting signs of 'winter kill' from Pond $6 \mathrm{~B}$ were systemically infected with Aeromonas hydrophila although no bacteria were found in the skin lesions. Based on these data we propose the following to explain the March observations: as water temperatures increase, bacteria begin to flourish and fish initially infected with the 'winter kill' fungus at colder temperatures subsequently succumb to bacterial infections at warmer temperatures. This proposal has been confirmed in laboratory challenge studies reported elsewhere (Bly et al. 1991). Another potential explanation for the lack of bacteria in fungusassociated skin lesions is that the fungus may inhibit the growth of other microorganisms. Many microorganisms which are in competition with each other, especially fungi, produce antimicrobials, for example the well-documented members of the genus Penicillium (Alderman \& Polglase 1986). In this regard, preliminary studies in our laboratory have revealed that Saprolegnia sp. produces an as yet unidentified antimicrobial agent(s) which inhibits the growth of other microorganisms (data not shown).

Various ideas (albeit undocumented) have been proposed concerning the involvement of water quality parameters as predisposing/causative factors in the syndrome termed 'winter kill'. In the challenge experiments reported here water quality was also routinely assayed, in particular to determine if high TAN and/or high un-ionized ammonia and/or low oxygen levels were causally associated with 'winter kill' in the laboratory. In all the laboratory challenge experiments conducted where tank water temperature was dropped from 22 to $10^{\circ} \mathrm{C}$ (comprising Protocols 2 and 4 to 10 ; Table 1), TAN values were initially low, $\leq 0.6 \mathrm{mg}^{-1}$, but steadily increased to 5.5 to $7.5 \mathrm{mg} \mathrm{l}^{-1}$ after $3 \mathrm{wk}$. Water $\mathrm{pH}$ values remained relatively constant during each experiment $( \pm 0.2)$, and between experiments 
ranged from 7.9 to 8.9 . Un-ionized ammonia levels were $<0.010 \mathrm{mg} \mathrm{l}^{-1}$ at the onset of the experiments and steadily increased to 0.500 to $0.650 \mathrm{mg} \mathrm{l}^{-1}$ after 3 wk. The increases in TAN and un-ionized ammonia values appeared dependent on the number and size of fish used in each experiment and increased regardless of whether or not fish were challenged or became infected (Table 1, Protocols 2 and 4 to 10). These results indicate that the high TAN levels, 10 and $8 \mathrm{mg} \mathrm{l}^{-1}$, and un-ionized ammonia levels, 0.182 and $0.145 \mathrm{mg} \mathrm{l}^{-1}$, recorded in Ponds $6 \mathrm{~B}$ and $16 \mathrm{~A}$, respectively, in January, were probably directly related to stocking density and likely had little or no direct bearing on the outbreak of 'winter kill'. In addition, the results of field studies have recently indicated that 'winter kill' can occur in ponds with low TAN (1.0 $\mathrm{mg} \mathrm{l}^{-1}$ ) and low unionized ammonia levels $\left(0.178 \mathrm{mg} \mathrm{l}^{-1}\right)$. This observation has been supported by the results of subsequent laboratory challenge experiments where low stocking densities were employed to maintain TAN levels $<1 \mathrm{mg} \mathrm{l}^{-1}$ while still achieving significant (70\%) mortalities (Bly et al. unpubl.). Furthermore, fish used in all the laboratory experiments originally came from and were challenged in well-oxygenated tanks (4 to $8 \mathrm{mg}$ $\mathrm{l}^{-1}$ ) indicating that a previous history of anoxia (which can be a problem in commercial catfish ponds during the summer months) is probably not a significant predisposing factor for an outbreak of 'winter kill'.

The observations made during our challenge experiments contradict studies wherein saprolegniosis is only observed in fish after handling, damage to the skin, overcrowding or in conjunction with pollution or bacterial or viral infections (reviewed in Pickering \& Willoughby 1982, Roberts 1989). Furthermore, when noninvasive challenge experiments were conducted by others relatively high levels of zoospores (50 to $100 \mathrm{ml}^{-1}$ ) were used (Wood et al. 1988). In our experiments, such high values were unlike pond situations and much lower levels of zoospores were found to rapidly infect catfish (Table 1, Protocols 7 to 10). The role of members of the genus Saprolegnia as primary pathogens is often debated because bacteria are also usually present in the lesions (Neish \& Hughs 1980, Noga \& Dykstra 1986). From our laboratory studies it is clear that Saprolegnia sp. can be an aggressive opportunistic pathogen for channel catfish without concomitant bacterial infection. It should be noted that although it was difficult to predict the exact number of Saprolegnia sp. zoospores produced from 1 infested hemp seed, some experiments represented in Protocol 7 (Table 1) had CF1 zoospores levels as low as 0,5 and 8 on Days 0 , 4 and 14 , and induced the following cumulative infected (dead) numbers in 15 fish challenged: 3(0), $10(8)$ and $15(13)$ on Days 8, 14 and 21, respectively. These results suggest that the low zoospore levels ( 5 to
$10 \mathrm{ml}^{-1}$ ) recorded in commercial catfish ponds may be sufficient to infect fish in those ponds if the fish are immunocompromised. Hence it is suggested that Saprolegnia sp. plays a key pathogenic role in the development of the skin lesions classically associated with 'winter kill' mortalities in channel catfish and that the disease be named 'winter saprolegniosis'.

In conclusion, the studies reported here provide the first working hypothesis describing the syndrome in channel catfish commonly termed 'winter kill'. The disease clearly involves complex reactions between 3 variables, namely a rapid decrease in water temperature to a low of ca $10^{\circ} \mathrm{C}$, in vivo immunosuppression in channel catfish, and a ubiquitous pathogen identified as a member of the genus Saprolegnia. Field studies are now being conducted to test this hypothesis.

Acknowledgements. We thank Mr T Arant and Mr L. Brown for the use of their ponds and catfish and $\mathrm{Mr} \mathrm{L}$. Thompson for the use of his juvenile catfish in this study. Thanks also are extended to Dr R.L.Seymour for his continuing help with fungal identification. We thank Dr G. Herrera for help with histopathology. Dr D. Bernanke for the use of his inverted microscope and camera, and Mr W. Revere for photography. This study was supported in part by NIH, grant 1-R37-AI19530, grant 2-S07RR05386 awarded by the Biomedical Support Grant Program, Division of Research, NIH, and by UDSA grant 90-34213-5135. A.J.S. was supported by a Natural Sciences and Engineering Research Council of Canada, Postdoctoral Fellowship 103181.

\section{LITERATURE CITED}

Alderman, D. J., Polglase, J. L. (1986). Aphanomyces astaci: isolation and culture. J Fish Dis. 9: 367-379

Alexopoulos, C. D., Mims, C. W. (1979). Introductory mycology, 3rd edn. John Wiley \& Sons, London

Amos, K. H. (1985). Procedures for the detection and identification of certain fish pathogens, 3rd edn. Fish Health Section, American Fisheries Society, Corvallis

Bly, J. E., Buttke, T. M., Meydrech, E. F., Clem, L. W. (1986). The effects of in vivo acclimation temperature on the fatty acid composition of channel catfish (Ictalurus punctatus) peripheral blood cells. Comp. Biochem. Physiol 83B: 791-795

Bly, J. E., Buttke, T. M., Cuchens, M. A., Clem, L. W. (1987). Temperature-mediated processes in teleost immunity: the effects of temperature on membrane immunoglobulin capping on channel catfish B lymphocytes. Comp. Biochem. Physiol. 88A: 65-70

Bly, J. E., Clem, L. W. (1988). Temperature-mediated processes in teleost immunity: homeoviscous adaptation by channel catfish peripheral blood cells. Comp. Biochem. Physiol. 91A: $481-485$

Bly, J. E., Clem, L. W. (1991a). Temperature-mediated processes in teleost immunity: in vitro immunosuppression induced by in vivo low temperature in channel catfish. Vet. Immunol. Immunopathol. 28: 365-377

Bly, J. E., Clem, L. W. (1991b). Temperature-mediated processes in teleost immunity: in vivo low temperature immuni- 
zation does not induce tolerance in channel catfish. Fish and Shellfish Immunol. 1 229-231

Bly, J. E., Cuchens, M. A., Clem, L. W (1988). Temperaturemediated processes in teleost immunity: differential abilities of channel catfish $I$ and $B$ lymphocytes to cap membrane antigen. Comp. Biochem. Physiol. 90A: 103-107

Bly, J. E., Lawson, L. A., Clem, L. W. (1991). Temperature effects on channel catfish immunity to a fungal pathogen. Dev. comp. Immun. N.Y 15: S1 Abs F2

Bly, J. E., Miller, N. W., Clem, L. W. (1990). Identification of a monoclonal antibody specific for channel catfish neutrophils and its use in studying stress-induced neutrophilia. Dev. comp. Immun. N.Y. 14(2): 211-222

Bullis, R. A., Noga, E. J., Levy, M. G. (1990). Immunological relationships of the fish-pathogenic oomycete Saprolegnia parasitic to other oomycetes and unrelated fungi. J. aquat. Anim. Hlth 2: 223-227

Coker, C. W. (1923). The Saprolegniaceae, with notes on other water molds. Univ, of North Carolina Press, Chapel Hill

Cossins, A. R., Bowler, K. (1987). Temperature biology of animals. Chapman \& Hall, New York

Durborow, R. M., Crosby, D. (1988). Monitoring winter kill conditions can cut losses. Catfish J. 3: 9

Ellsaesser, C. F., Clem, L. W. (1986). Hematological and immunological changes in channel catfish stressed by handling and transport. J. Fish Biol. 28: 511-521

Emerson, K., Russo, R. C., Lund, R. E., Thurston, R. V. (1975) Aqueous ammonia equilibrium calculations: effects of $\mathrm{pH}$ and temperature. J. Fish. Rs. Bd Can. 32: 2379-2383.

Faulmann, E., Cuchens, M. A., Lobb, C. J., Miller, N. W., Clem, L. W. (1983). An effective culture system for studying in vitro mitogenic responses of channel catfish lymphocytes. Trans. Am. Fish. Soc. 112: 673-679

Hazel, J. R. (1984). Effects of temperature on the structure and metabolism of cell membranes in fish. Am. J. Physiol. 246 R460-R470

Joklik, W. K., Willett, H. P., Amos, D. B., Wilfert, C. M. (1988) Zinsser microbiology. Appleton \& Lange, Norwalk, p. 3

Koch, R. (1884). Die aetiologie der Tuberkulose. Mitt. Kaiserl. Gesundheitsamt 2: 1-88

MacMillan, J. R., Santucci, T (1990). Seasonal trends in intes-

Responsible Subject Editor: T Evelyn, Nanaimo, B. C., Canada tinal bacterial flora of farm-raised channel catfish. J. aquat. Anim. Hlth 2: 217-222

Miller, N. W., Deuter, A., Clem, L. W (1986). Phylogeny of lymphocyte herogeneity; the cellular requirements for the mixed leukocyte reaction with channel catfish. Immunology 59: 123-128

Neish, G. A., Hughes, G. C. (1980). Diseases of fishes, Book 6. Fungal diseases of fishes. TFH Publications, Neptune

Noga, E. J., Dykstra, M. J. (1986). Oomycete fungi associated with ulcerative mycosis in menhaden, Brevoortia tyrannus (Latrobe). J. Fish Dis. 9: 47-53

Pickering, A. D., Willoughby, L. G. (1982). Saprolegnia infections of salmonid fish. In: Roberts, R. J. (ed.) Microbial diseases of fish. Academic Press Inc., London, p. 27 1-297.

Roberts, R. J. (1989). Fish pathology. Balliere Tindall, London

Schnur, L. F., Sarfstein, R., Jaffe, C. L. (1990). Monoclonal antibodies against leishmanial membranes react with specific excreted factors $(E F)$. Ann. Trop. Med. Parasit. $84(5): 447-456$

Seymour, R. L. (1970). The genus Saprolegnia. Nova Hedwigia 19: 1-124

Sinensky, M. (1974). Homeoviscous adaptation - a homeostatic process that regulates viscosity of membrane lipids in Escherichia coli. Proc. natl Acad. Sci. U.S.A. 7 522-525

Taguchi, H., Tanaka, R., Nishimura, K., Miyaji, M. (1988) Application of flow cytometry to differentiating Exophiala dermatitidis, $E$. moniliae and $E$. jeanselmei from each other. Mycopathologia 103: 87-90

Thompson-Carter, F. M., Carter, P. E., Pennington, T H (1989). Differentiation of staphylococcal species and strains by ribosomal RNA gene restriction patterns. J gen. Microbiol. 135: 2093-1097

Willoughby, L. G., Pickering, A. D. (1977). Viable Saprolegniaceae spores on the epidermis of the salmonid fish Salmo trutta and Salvelinus alpinus. Trans. Br mycol. Soc. 68: 91-95

Wood, S. E., Willoughby, L. G., Beakes, G. W (1988). Experimental studies on uptake and interaction of spores of the Saprolegnia diclina-parisitica complex with the external mucus of brown trout (Salmo trutta). Trans. Br. mycol. Soc. 90(1): $63-73$

Manuscript first received: December 31, 1991

Revised version accepted: June 1, 1992 